\title{
In Response to COVID-19: Frontline Experience in a Tertiary Obstetrics and Gynecology Hospital
}

\author{
Allison Tan CS ${ }^{1}$, Lily Kho CL ${ }^{1 *}$, Tan Shu Qi ${ }^{1}$, Rajeswari Kathirvel ${ }^{1,2}$, Suzanna Sulaiman ${ }^{1,2}$ \\ ${ }^{1}$ Department of Obstetrics and Gynecology, KK Women's and Children's Hospital, Singapore \\ ${ }^{2}$ Lee Kong Chian school of Medicine, Yong Loo Lin School of Medicine, Duke-NUS Medical School, Singapore \\ *Corresponding author: Lily Kho CL, Associate Consultant, Department of Obstetrics and Gynecology, KK Women's and Children's
} Hospital, +65 6225 5554, 100 Bukit Timah Road, Singapore 229899

Received date: July 08, 2020; Accepted date: July 12, 2020; Published date: July 20, 2020

Citation: Allison Tan CS, Lily Kho CL, Tan Shu Qi, Kathirvel R, Sulaiman S., (2020) In Response to COVID-19: Frontline Experience in a Tertiary Obstetrics and Gynecology Hospital. J Women Health Care Issues. J Women Health Care Issues, 3(3); Doi:10.31579/2642-9756/031

Copyright: @ 2020 Lily Kho CL, This is an open access article distributed under the Creative Commons Attribution License, which permits unrestricted use, distribution, and reproduction in any medium, provided the original work is properly cited.

\section{Abstract}

The COVID-19 pandemic has taken the world by storm, with the medical industry bearing the brunt of the outbreak. Singapore was one of the earliest countries outside of China to be affected by the outbreak, and the nation's healthcare sector had to react quickly in order to maintain continuity of care. This commentary is a narrative review of our center's dynamic response to the evolving COVID-19 pandemic. We reviewed the logistical considerations and workflow modifications made by our center following the outbreak. We compared our protocols with local and international guidelines by performing a literature review. Logistical considerations taken into account included the designation of an isolation area and a dedicated team to run the area. Workflow modifications made included triaging patients into isolation and non isolation groups, modifying protocols for patients requiring admission or transfer to other tertiary institutions, and starting a Swab and Send Home Protocol for discharge. The COVID-19 pandemic has taught us that response to an evolving outbreak is dynamic and continued reassessment of processes and workflows in place is the key to help us curb this outbreak.

Keywords: communicable disease; gynecology; pandemics; workflow

\section{Introduction:}

The COVID-19 outbreak is an ongoing pandemic that has taken the world by storm. As of $31^{\text {st }}$ May 2020, there has been more than 6 million confirmed cases, including 371,000 deaths [1]. Singapore was one of the earliest countries affected by COVID-19, with the first case diagnosed on $23^{\text {rd }}$ January 2020. By $31^{\text {st }}$ May 2020, the nation reported 34,884 cases (the highest number in Southeast Asia) and 23 deaths [2]. In response to the outbreak, the Ministry of Health (MOH) raised the Disease Outbreak Response System Condition (DORSCON) from yellow to orange on $7^{\text {th }}$ February $2020^{[3]}$. This emphasized the urgency of containing the disease, inhibiting person to person spread. The country further declared a 'Circuit Breaker', implementing a stringent set of social distancing measures from $7^{\text {th }}$ April 2020 to $1^{\text {st }}$ June 2020.

KK Women's and Children's Hospital (KKH) is Singapore's largest hospital, exclusively treating children and women with obstetrics and gynecology $(\mathrm{O} \& \mathrm{G})$ conditions. Its Urgent Obstetrics and Gynecology Centre (UOGC) is a 24-hour walk-in center for women with acute O\&G conditions. Approximately 2,700 patients access this service every month.
The COVID-19 pandemic posed several challenges to UOGC's daily operation, being one of the "gatekeepers" for the hospital. This article is a narrative review of our center's quick and dynamic response to the evolving outbreak in order to maintain continuity of care.

\section{Methods}

We systemically reviewed the logistical considerations and workflow modifications made by UOGC in response to the COVID-19 outbreak. We analyzed and evaluated all policy changes made by our center, and ensured that they were kept up to date with the evolving outbreak and the latest evidence on the condition. We compared and cross-checked our protocols with local and international guidelines by performing a literature review. We reviewed articles concerning the responses made to contain the COVID-19 outbreak and manage the disease. We included all articles that were written in the English language, with no restriction placed on country. We also critically reviewed the difficulties and challenges that our center had faced and the measures taken to overcome them. 


\section{Results and Discussion}

\section{Logistical considerations}

Logistics was one of the first factors considered and has been vital in ensuring the UOGC's continuity of care during the COVID-19 outbreak.

As one of the initial measures implemented, the UOGC designated an isolation area that was physically separate from the main center [4]. Three negative pressure consultation rooms have been assigned solely for the review of patients in isolation, alongside a segregated waiting area where patients are seated one meter apart. One consultation room is equipped with an ultrasound machine to minimize cross contamination from the movement of patients in isolation to other departments for imaging. The consultation rooms are thoroughly cleaned and sanitized after each ca

Hospital transmission has shown to pose a serious threat to healthcare personnel and patients [5]. To prevent cross contamination within UOGC and other areas of the hospital, a dedicated team of doctors and nurses is scheduled to service the isolation area. Each team consists of a senior and junior doctor, and two nurses working 12-hour shifts for 7 days in a row. Additional support is provided by a separate team consisting of Obstetricians, Gynecologists and Infectious Disease (ID) physicians. This arrangement ensured that patient safety and quality of care were not compromised during the crisis.

Pre-existing standard precautions included the practice of good hand hygiene. The UOGC adopted additional droplet and airborne precautions in the form of enhanced Personal Protection Equipment (PPE) in response to the outbreak [6]. This includes the use of N95 masks, gowns, gloves, goggles or visors and head caps. The Powered Air-Purifying Respirator (PAPR) is used for collection of nasopharyngeal swabs for COVID-19 testing or when performing any aerosol-inducing procedure. At the early stages of the outbreak, all hospital staff were fitted with appropriate size N95 masks and trained on the proper sequence of donning and removing PPE.

Apart from goggles and visors, the enhanced PPE is single use. A new set is donned for each patient. Used PPE items are discarded into biohazard bags. The housekeepers in enhanced PPE then perform terminal cleaning on the consultation room after each use and promptly dispose of these biohazard bags. Equipment is cleaned and disinfected between use.

\section{Workflow considerations}

Another key aspect of UOGC's response to COVID-19 is its operational changes on the journey of patients in isolation (Figure. 1).

Fig. 1 Flowchart depicting the journey of patients in isolation

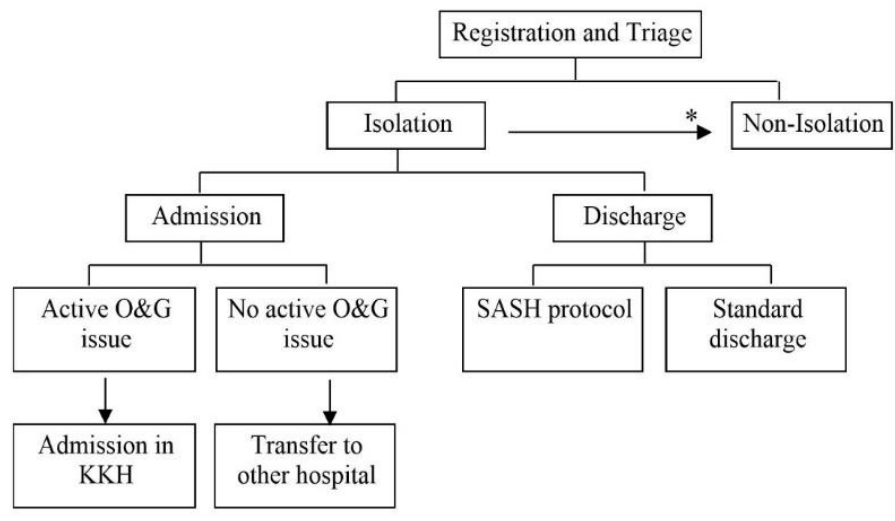

*Patients can be de-isolated following review by the isolation doctor.

\section{Figure 1: Flowchart depicting the journey of patients in isolation}

Patients were given a mask on entry into UOGC until it was made mandatory by the government for everyone to wear a mask outside their home. Each patient completes a declaration form used to stratify their risk.
Patients with travel history, contact history with anyone suspected or confirmed to have COVID-19, fever, or acute respiratory symptoms are immediately isolated. Accompanying persons are submitted to the same 
J Women Health Care Issues

screening criteria. The triage criteria is regularly updated based on the "suspect case" definition revisions by $\mathrm{MOH}$ [7]. in response to the evolving pandemic. During its first week of implementation, a positive travel history only included patients with recent travel to mainland China. This quickly expanded to include South Korea, then Japan, before finally including all persons with any travel history outside of Singapore following the significant rise in COVID-19 cases globally.

In addition to a standard obstetric and gynecological history and examination, a detailed history of patients' respiratory symptoms, travel, and contact history are obtained. A dedicated team of ID physicians are readily available for phone consultation at all times. Patients deemed to be at low risk after review by the isolation doctor are transferred to general wards. The workflow has been regularly updated based on the evolving evidence on the condition.

The UOGC implemented protocols for isolated patients requiring formal imaging. When needed, portable chest radiographs were performed by radiographers in enhanced PPE within the isolation area. When these patients required formal ultrasound scans, they were transferred to the radiology department after alerting the relevant personnel in advance. The scan would then be performed by the radiologist in enhanced PPE in a dedicated isolation room.

High risk treatment procedures such as nebulization [8]. were administered in an alternative form with a metered-dose inhaler. Where this is not possible, nebulization was administered in an isolation room in PAPR.

To minimize cross-contamination, the center carefully planned the movement of isolated patients. In addition to a nurse and porter, patients for hospitalization are escorted by two security officers in enhanced PPE to the designated isolation ward. The security officers play a vital role in ensuring that the patients in isolation do not come into close proximity with others by navigating the route. Lifts used are thoroughly disinfected immediately after.
Copy rights@ Lily Kho CL,

The UOGC also initiated a Swab and Send Home (SASH) protocol for patients with fever or acute respiratory symptoms who did not have active gynecological issues requiring admission. Prior to its implementation, all patients requiring COVID-19 swab testing were admitted. The SASH protocol eliminated the need for admission of these stable patients. Instead, these patients are issued a five-day hospitalization leave, during which they have to remain isolated at home by law. They are given clear discharge advice defining the precautionary measures they should take as advised by the $\mathrm{MOH}$ and to return for further medical attention should their condition worsen. These swab results are communicated to the patients by the isolation team in a timely fashion.

A porter collects the discharge medication from the pharmacy on behalf of these patients to further minimize social contact.

Being exclusively an $\mathrm{O} \& \mathrm{G}$ hospital, patients presenting with non-O\&G issues are transferred to other general hospitals. The UOGC modified the workflow to reduce unnecessary contamination in the receiving hospital by transferring isolated patients in a dedicated ambulance, and offering direct admission to isolation areas of the receiving hospital.

\section{Challenges faced}

Setting up the isolation area was challenging. The department had to take into account the flow of patients through the center, whilst ensuring segregation of other patients from those requiring isolation. The center was able to achieve this with no impact on UOGC services and without having to create makeshift temporary clinics.

Response to an evolving outbreak is dynamic and the UOGC isolation team has to be quick to adapt to the latest recommendations by the hospital and $\mathrm{MOH}$. (Figure. 2) illustrates the timeline of changes implemented in UOGC. Our team works closely with the ID department, and regularly reviews and revises our protocols. 
Fig. 2 Timeline of key events and interventions

\begin{tabular}{|c|c|}
\hline Measures by MOH & Measures by UOGC \\
\hline $\begin{array}{l}\mathbf{2 3 / 0 1 / 2 0 2 0} \\
\text { First confirmed case of COVID-19 in } \\
\text { Singapore }\end{array}$ & \\
\hline $\begin{array}{l}\mathbf{2 5 / 0 1 / 2 0 2 0} \\
\text { First revision of suspect case definition by } \\
\text { MOH, to include all travel history to } \\
\text { mainland China }\end{array}$ & $\begin{array}{l}\mathbf{0 6 / 0 2 / 2 0 2 0} \\
\text { Staff trained on the use of PAPR }\end{array}$ \\
\hline $\begin{array}{l}\mathbf{0 7 / 0 2 / 2 0 2 0} \\
\text { MOH raised the DORSCON level to Orange }\end{array}$ & $\begin{array}{l}\mathbf{0 7 / 0 2 / 2 0 2 0} \\
\text { UOGC began operation of ISO }\end{array}$ \\
\hline & $\begin{array}{l}\text { 09/02/2020 } \\
\text { Patients requiring inpatient treatment } \\
\text { admitted to designated isolation ward. } \\
\text { Initiated protocol for transfer of isolated } \\
\text { patients within the hospital }\end{array}$ \\
\hline & $\begin{array}{l}\text { 10/02/2020 } \\
\text { Started pre triage temperature screening of all } \\
\text { patients and caregivers. }\end{array}$ \\
\hline $\begin{array}{l}\mathbf{2 3 / 0 2 / 2 0 2 0} \\
\text { Revision of suspect case definition by MOH, } \\
\text { to include travel history to Daegu City or } \\
\text { Cheongdo County in South Korea }\end{array}$ & $\begin{array}{l}\mathbf{1 2 / 0 2 / 2 0 2 0} \\
\text { In house COVID-19 swab testing made } \\
\text { available, swabs no longer sent to other } \\
\text { institutions for processing }\end{array}$ \\
\hline $\begin{array}{l}\mathbf{0 3 / 0 3 / 2 0 2 0} \\
\text { Revision of suspect case definition by MOH, } \\
\text { to include travel history to Republic of } \\
\text { Korea, Japan, Northern Italy (including } \\
\text { Milan and Venice), and Iran }\end{array}$ & \\
\hline $\begin{array}{l}\mathbf{0 9 / 0 3 / 2 0 2 0} \\
\text { Revision of suspect case definition by } \mathrm{MOH}, \\
\text { to include travel history to any country } \\
\text { outside of Singapore }\end{array}$ & $\begin{array}{l}06 / 03 / 2020 \\
\text { Isolation criteria expanded to include all } \\
\text { patients with fever regardless of source of } \\
\text { fever }\end{array}$ \\
\hline $\begin{array}{l}\text { 30/03/2020 } \\
\text { First dormitory cluster identified in } \\
\text { Singapore }\end{array}$ & \\
\hline $\begin{array}{l}\text { 07/04/2020 } \\
\text { Start of 'Circuit Breaker' by MOH }\end{array}$ & $\begin{array}{l}\mathbf{0 8 / 0 4 / 2 0 2 0} \\
\text { Initiation of SASH protocol. Stable patients } \\
\text { no longer required admission for COVID-19 } \\
\text { swab testing }\end{array}$ \\
\hline $\begin{array}{l}\text { 14/04/2020 } \\
\text { Wearing of masks outside of homes made } \\
\text { mandatory by law }\end{array}$ & $\begin{array}{l}\mathbf{1 8 / 0 4 / 2 0 2 0} \\
\text { Assisted national effort of aggressive } \\
\text { COVID-19 testing in dormitories by helping } \\
\text { to dispatch COVID- } 19 \text { swabs }\end{array}$ \\
\hline $\begin{array}{l}01 / 06 / 2020 \\
\text { End of circuit breaker }\end{array}$ & \\
\hline
\end{tabular}

\section{Figure 2: Timeline of key events and interventions}

Another challenge encountered was false declarations made by patients at triage. This compromised the safety of our staff and other patients.
Patients are forewarned of the consequences of false declaration, which may lead to prosecution under the Infectious Disease Act [9]. Patients 
found to have breached Stay Home Notice or made false declarations were reported to the relevant government authorities.

The welfare of the isolation team is a key priority for our department. Stress and fatigue from working in the frontlines for extended shift hours are inevitable ${ }^{[10]}$. Dedicated en-suite call rooms are allocated to the isolation team to avoid cross contamination with the regular on-call team. Unwell staff are encouraged to seek medical attention and given medical leave. Doctors are granted dedicated rest following their week-long service. The hospital instituted a dedicated phone line for staff requiring mental and emotional support. Senior doctors took on shared workload to reduce manpower fatigue amongst the juniors. Regular feedback is gathered to optimize working conditions and streamline the workflow. The isolation team has received strong support from members of the public via letters of encouragement and gifts of gratitude.

\section{Conclusion}

Since the isolation team began operation, the UOGC has seen a total of 958 cases. As Singapore prepares for the next phases of 'Post Circuit breaker', the UOGC recognizes the importance of continued vigilance. This crisis has challenged the center's ability to respond swiftly to an evolving pandemic. Continued reassessment and dynamic reviews of processes and workflows in place is the key to help us curb this outbreak and to prepare for the future.

\section{Acknowledgements}

The authors thank nurse clinician Riza Tungul; doctors, nurses, and support staff of the Urgent Obstetrics and Gynecological Centre especially the dedicated "Isolation" teams; the Department of Obstetrics \& Gynecology; Department of Infectious Diseases; Division of Obstetrics and Gynecology, KK Women's and Children's Hospital, Singapore.

\section{Disclosure of Interest}

No conflict of interest from members of the study.

\section{Contribution to Authorship}

All authors contributed to study conceptualization and design. ATCS wrote the original manuscript. The rest of the authors critically reviewed the content. All the authors have reviewed and approved the final version of the manuscript.

\section{Details of Ethics Approval}

No ethics approval.

Funding

No funding required.

\section{References}

1. Covid19.who.int. 2020. WHO Coronavirus Disease (COVID19) Dashboard. [online] Available at:

2. Moh.gov.sg. 2020. MOH | Updates On COVID-19 (Coronavirus Disease 2019) Local Situation.

3. Moh.gov.sg. 2020. MOH | News Highlights.

4. Wilder-Smith, A. and Freedman, D., 2020. Isolation, quarantine, social distancing and community containment: pivotal role for old-style public health measures in the novel coronavirus (2019-nCoV) outbreak. Journal of Travel Medicine, 27(2).

5. Wee, L., Conceicao, E., Sim, X., Aung, M., Tan, K., Wong, H., Wijaya, L., Tan, B., Ling, M. and Venkatachalam, I., (2020) Minimizing intra-hospital transmission of COVID-19: the role of social distancing. Journal of Hospital Infection, 105(2), pp.113-115.

6. Who.int. 2020. Infection Prevention And Control During Health Care When Novel Coronavirus (Ncov) Infection Is Suspected.

7. Ministry of Health, 2020. Revision Of Suspect Case Definition For Coronavirus Disease 2019 (COVID 19) And Swab-AndSend-Home Criteria. Singapore. [Accessed 28 May 2020].

8. Amirav, I. and Newhouse, M., 2020. Transmission of coronavirus by nebulizer: a serious, underappreciated risk. Canadian Medical Association Journal, 192(13), pp.E346E346.

9. Singapore Statutes Online. 2020. Infectious Disease Act 21A

10. Chua, M., Lee, J., Sulaiman, S. and Tan, H., 2020. From the frontline of COVID-19 - how prepared are we as obstetricians? A commentary. BJOG: An International Journal of Obstetrics \& Gynecology, 127(7), pp.786-788 
This work is licensed under Creative

Commons Attribution 4.0 License

To Submit Your Article Click Here: Submit Article

DOI:10.31579/2642-9756/031
Ready to submit your research? Choose Auctores and benefit from:

* fast, convenient online submission

* rigorous peer review by experienced research in your field

* rapid publication on acceptance

* authors retain copyrights

* unique DOI for all articles

* immediate, unrestricted online access

At Auctores, research is always in progress.

Learn more https://www.auctoresonline.org/journals/women-health-careand-issues 